BULLETIN Bulletin hispanique

HISPANIQUE Université Michel de Montaigne Bordeaux

$118-2$ | 2016

Varia

\title{
El Seminario de Estudios Sociológicos de la Mujer
} (1960-1986)

Investigación y reivindicación feminista del Tardofranquismo a la Transición

Begoña Barrera López

\section{OpenEdition}

Journals

Edición electrónica

URL: http://journals.openedition.org/bulletinhispanique/4601

DOI: 10.4000/bulletinhispanique.4601

ISSN: 1775-3821

Editor

Presses universitaires de Bordeaux

Edición impresa

Fecha de publicación: 15 diciembre 2016

Paginación: 611-628

ISBN: 979-10-300-0125-9

ISSN: 0007-4640

Referencia electrónica

Begoña Barrera López, «El Seminario de Estudios Sociológicos de la Mujer (1960-1986) », Bulletin hispanique [En línea], 118-2 | 2016, Publicado el 15 diciembre 2019, consultado el 31 diciembre 2019. URL : http://journals.openedition.org/bulletinhispanique/4601 ; DOI : 10.4000/bulletinhispanique.4601 


\title{
El Seminario de Estudios Sociológicos de la Mujer (1960-1986). Investigación y reivindicación feminista del Tardofranquismo a la Transición
}

\author{
Begoña Barrera López \\ Universidad de Sevilla
}

Le Séminaire d'Études Sociologiques sur la Femme est un groupe de travail, fondé par Maria Laffitte, qui a été actif entre 1960 et 1986. Composé de femmes aux trajectoires intellectuelles remarquables, il a mené d'importants travaux de recherche sur la situation de la femme espagnole et il a été progressivement intégré au mouvement des femmes qui se développait parallèlement en Espagne.

Mots-Clés : séminaire d'études sociologiques sur la femme, féminisme et franquisme tardif, féminisme et transition, mouvement des femmes, culture féministe, identités et genre.

El Seminario de Estudios Sociológicos de la Mujer fue un grupo de trabajo fundado por María Laffitte y activo entre los ańos 1960 y 1986. Integrado por mujeres de reconocida trayectoria intelectual, desarrolló una dilatada labor de investigación sobre la situación de la mujer española y fue integrándose progresivamente en el movimiento de mujeres que se estaba desarrollando de forma paralela en España.

Palabras clave: seminario de estudios sociológicos de la mujer, feminismo tardofranquismo, feminismo y transición, movimiento de mujeres, cultura feminista, identidades de género.

The Seminar for Women's Sociological Studies is a workgroup founded by María Laffitte, which developed its activites between 1960 and 1986. This Seminar comprised several women with remarkable intellectual careers who wanted to deepen in the research about Spanish women's social situations. Progressively, the SESM was integrated into the women's movement developing in Spain at the same time.

Keywords: Seminary for Sociological Women Studies, Late-Francoism feminism, feminism during Transition, women's movement, feminist culture, gender identities. 


\section{INTERESES COMPARTIDOS Y UN PROYECTO EN COMÚN}

En 1960 un grupo de mujeres de trayectoria intelectual diversa, pero coincidente en su rechazo compartido hacia el modelo de mujer promovido y oficializado por el discurso franquista, se constituyó como Seminario de Estudios Sociológicos de la Mujer (SESM) ${ }^{1}$. María Laffitte, escritora, feminista, crítica de arte y fundadora del grupo ${ }^{2}$, afirmaría en 1983 que el propósito que con ello habían perseguido era «despertar las conciencias especialmente somnolientas de las mujeres espańolas»" ${ }^{3}$. Sin embargo, y como complemento de esa declaración, habría que añadir que si bien es a partir de 1960 cuando aquellas ocho mujeres fundadoras se plantearon estudiar colectivamente la entonces denominada "cuestión de la mujer», lo cierto es que con anterioridad muchas de ellas ya habían abordado esta problemática.

Laffitte, fundadora y directora del SESM hasta 1980, fue sin duda un caso paradigmático de compromiso con esta cuestión. Varias obras escritas desde la década de los cuarenta y dedicadas a abordar desde perspectivas teóricas y filosóficas acreditaron su interés por teorizar sobre los conceptos de «mujer» y de "feminidad», y por reflexionar acerca de la situación actual de la mujer española (Maria Blanchard, 1944; La secreta guerra de los sexos, 1948; La mujer como mito y como ser humano, 1961; La mujer en España. Cien años de su historia (1860-1969)). A finales de los años cincuenta, su convencimiento acerca de la necesidad de construir un ambicioso proyecto de investigación que abordara de forma sistemática el proceso de transformación que por entonces vivía la mujer espańola la condujo al convencimiento de que el mejor modo de abordar esta cuestión sería a través del trabajo colectivo. Así, en 1960, por mediación de su amiga Lilí Álvarez, consiguió reunir a un grupo de mujeres que cumplían el perfil que la escritora había establecido como necesario para integrar el Seminario: «que todas ellas fueran universitarias y que ejercieran una profesión a fin de que tuvieran una experiencia directa de lo que era, por entonces, el mundo del trabajo para la mujer $\aleph^{4}$.

Integraron esta selección Consuelo de la Gándara, antigua estudiante de la Institución Libre de Enseñanza y en aquel momento profesora de lengua y literatura italiana en la Universidad Complutense de Madrid; su amiga Elena Catena, profesora de literatura espańola de la misma Universidad y colaboradora de la editorial Castalia; las hermanas Pura y Mary Salas Larrazábal, esta última

1. Una primera versión de este trabajo fue galardonado en diciembre de 2015 con el Accésit del XVIII Premio SIEM (Seminario Interdisciplinar de Estudios de la Mujer) de Investigación Feminista «Concepción Gimeno de Flaquer», de la Universidad de Zaragoza. Su contenido ha permanecido inédito por voluntad de la autora.

2. Para un análisis completo de la trayectoria de María Laffitte, véase Begoña Barrera, María Laffitte. Una biografía intelectual. Sevilla, Editorial Universidad de Sevilla, 2015.

3. María Laffitte, Mi atardecer entre dos mundos. Recuerdos y cavilaciones. Madrid, Planeta, 1983, p. 122.

4. María Laffitte, Mi atardecer..., 1983, p. 122-123. 
famosa por haber publicado en 1959 el libro Nosotras las solteras, donde trataba de visibilizar a estas mujeres marginadas por la sociedad tradicional. Si su papel resultó especialmente importante para el SESM fue, en gran medida, debido a que se convirtió en punto de contacto de las distintas redes femeninas católicas, puesto que ella misma era dirigente nacional de Acción Católica5. También formaron parte del SESM Concepción Borreguero Sierra, formada en Ciencias Políticas y con amplios conocimientos de sociología (fundamentales para el desarrollo del Seminario como se verá más abajo); María Jiménez de Obispo del Valle, licenciada en Derecho y en Ciencias Sociales; y la ya mencionada Lilí Álvarez, que contaba con un importante recorrido intelectual ligado a las reivindicaciones feministas católicas. Así, en su libro En tierra extraña (1954) y en El seglarismo y su identidad (1959) Álvarez había demandado una inclusión mayor de la mujer en muchos ámbitos religiosos. Ya en 1965 publicaría Feminismo y espiritualidad, donde afirmaba que el proceso de promoción de la mujer había de fundamentarse en dos propuestas: la emancipación de su estado de dependencia y pasividad, y la toma de conciencia de los derechos y deberes que le conducirín a su total incorporación a la sociedad y a las tareas colectivas $^{6}$.

Junto con el cuestionamiento firme de los paradigmas de mujer franquista, el grupo tuvo como principal propósito averiguar cómo se estaba desarrollando el proceso de integración de la mujer en la modernización del país ${ }^{7}$. Así, al afirmar la escritora que su objetivo era poner en movimiento un grupo que estudiase a fondo «la problemática sociológica que en aquellos momentos tenía planteado el mundo femenino", estaba declarando su intención de tomar el pulso al proceso de transformación de la mujer desde una perspectiva que no estuviera mediada por los discursos oficiales, puesto que, como la propia Laffitte aseguraba, «es sabido que todo lo concerniente a este tema [la mujer] se encontraba, por aquel entonces, totalmente monopolizado por la Sección Femenina» ${ }^{8}$.

5. Mónica Moreno Seco, «Cristianas por el feminismo y la democracia. Catolicismo femenino y movilización en los años setenta», Historia Social, 53, 2005, pp. 137-154, p. 143.

6. Teresa Rodríguez de Lecea, "Mujer y pensamiento religioso en el franquismo», Ayer, 15, 1995, pp. 177-200; Carmen Valiente Fernández, «¿Por qué protestan las mujeres? La resistencia feminista en la Iglesia Católica de España durante el primer franquismo", Nuevos horizontes del pasado. Culturas politicas, identidades y formas de representación: Actas del X Congreso de la Asociación de Historia Contemporánea, Ángeles Barrio Alonso, Jorge de Hoyos Puente, y Arias Saavedra (eds.), Madrid, 2011.

7. La calificación de feminista se la atribuye el propio SESM en un texto publicado en el año de su disolución, 1986: SESM: «El movimiento feminista en España. De 1960 a 1980», en Concha Borreguero y Elena Catena, La mujer española: de la tradición a la modernidad (19601980). Madrid, Tecnos, p. 31.

8. María Laffitte, Mi atardecer..., op. cit., p. 122. 


\section{Hacia el CUeSTiOnamiento PÚblico de LOS MOdelos OfiCiales}

En 1939 y con motivo de un homenaje que la Sección Femenina (SF) bridaba a Franco, este recordaba a las mujeres de la organización falangista que «no acabó vuestra labor con la realizada en los frentes [...] os queda la reconquista del hogar. Os queda formar a los niños y a las mujeres españolas»?. Así, a la Sección Femenina le fue encomendado el encuadramiento de las mujeres españolas mediante una "formación integral» que, sin embargo, antes que un carácter educativo, tuvo más bien, y sobre todo en sus primeros ańos, una naturaleza de adoctrinamiento sin cuartel. Los cauces para recuperar a la «auténtica mujer espańola», supuestamente perdida y deformada entre las malsanas modernidades de épocas anteriores, fueron numerosos, y se hicieron posibles gracias al despliegue por toda la geografía española de su compleja y eficaz red de jerarquías políticas y de servicio. Si bien durante los años de postguerra, y aún los primeros de la década de los cincuenta, la organización dirigida por Pilar Primo de Rivera contó con una amplia hegemonía en el campo de la formación de las españolas, así como una amplia cobertura cultural para la difusión de sus consignas, a finales de la década señalada los cambios sociales le hicieron cambiar de estrategia. Contradiciendo en gran medida su discurso anterior sobre la domesticidad y la dedicación plena de la mujer al hogar y la familia, la SF empezó a dar muestras públicas de una preocupación por favorecer el trabajo femenino, y promovió hasta tres leyes en este sentido: la reforma del Código Civil, en 1958; la Ley de Derechos Políticos, Profesionales y de Trabajo de la Mujer, en 1961; y las enmiendas que se efectuaron sobre esta última, en 1966.

El Fuero del Trabajo promulgado en 1938 había estipulado fuertes restricciones laborales bajo el argumento de la necesidad de «liberar a las mujeres casadas del taller y de la fábrica" y devolverlas a sus hogares. A sabiendas de la insuficiencia de este marco legislativo, y consciente de su posición privilegiada para promover cambios moderados que, aunque modernizaran, continuaran vinculando a la mujer al espacio tutelado (hogar), Pilar Primo de Rivera solicitó a Mercedes Formica, abogada y afiliada fundadora de la SF, la elaboración de un documento en el que se recogieran tanto la situación del empleo femenino como las reformas que parecieran necesarias. Este informe, cuya presentación estaba prevista para una de las sesiones del Congreso Femenino Hispanoamericano de 1951, fue finalmente excluido ${ }^{10}$.

9. «Discurso pronunciado con motivo del homenaje de la Sección Femenina al Caudillo y al Ejército de España. Medina del Campo, 30 de mayo de 1939», en Francisco Franco, Palabras del Caudillo, Madrid, Editora Nacional, 1943, pp. 211-216. Esto queda oficialmente reconocido en el Decreto del 28 de diciembre de 1939 sobre funciones de la Sección Femenina de FET y las JONS.

10. No obstante, sus contenidos fueron empleados, sin permiso de Formica, para la elaboración de una serie de documentos de opinión escritos por la SF y dirigidos a la Dirección 
En lo sucesivo, Formica emplearía otras plataformas aparte de la SF para mostrar sus opiniones acerca de las necesarias reformas del Código Civil. En 1952 comenzó a colaborar con el diario $A B C$, donde en noviembre aparecería su conocido artículo "Domicilio conyugal». Tomando como referente para su argumentación el reciente asesinato de una mujer a manos de su marido, la abogada denunciaba el terrible sesgo discriminatorio de la legislación española, que no solo subordinaba llamativamente a las mujeres respecto de los hombres, sino que, en el caso de las casadas, dificultaba enormemente que la esposa se separara de su marido. Formica concluía que la doble vara de medir del Código Civil estaba en la base de sucesos como aquel asesinato, y sentenciaba: «hoy, esta parcialidad, lleva a doce cuchilladas». ${ }^{11} \mathrm{La}$ encendida polémica que suscitaron sus palabras se reflejó en el acalorado debate que tuvo lugar en las páginas de $A B C$ durante las siguientes semanas acerca de la situación de la mujer en la legislación española, una discusión que además tuvo su correspondencia en las propuestas llevadas ante las Cortes en los años posteriores. Así, en 1958, Formica volvería a jugar un papel esencial al promover -esta vez con el apoyo declarado de Primo de Rivera- la reforma del Código Civil de $1958^{12}$. Aunque del todo insuficiente, con ella se empezaban a andar los primeros pasos hacia la igualdad entre ambos cónyuges. ${ }^{13}$ Posteriormente, con la aprobación en 1961 de la Ley de Derechos Políticos, Profesionales y de Trabajo de la Mujer, la discriminación legal de la mujer disminuyó en cuestiones como el adulterio, la viudedad, y la separación legal. Pese a ello, la situación jurídica de las mujeres quedaba aún lejos de ser equiparable a la del hombre. No en vano, Primo de Rivera, a quien se la consideró junto a la SF como artífice de la ley ${ }^{14}$, en su presentación ante las Cortes aseguraba que «no es ni por asomo una ley feminista; seríamos infieles a José Antonio si tal hiciéramos» ${ }^{15}$.

En 1968, en un ejercicio de regresión sobre lo andado, Primo de Rivera volvía a las Cortes para defender una nueva propuesta de ley sobre el «trabajo doméstico, extradoméstico de la mujer casada con responsabilidades familiares». La Delegada Nacional señaló la necesidad de crear lo que denominaba la «renta del ama de casa», lo cual «revolucionar[ía] el concepto y consideración del trabajo y la vida doméstica de la mujer ${ }^{16}$. No se puede decir que este propósito fuera una invención de aquellas fechas. Apenas diez años antes, en

General del Trabajo en 1952. Cfr.: Mercedes Formica, A instancia de parte. Madrid, Castalia, 1991, pp. 36-37; y Kathleen Richmond, Las mujeres en el fascismo español..., op. cit., p. 172.

11. Mercedes Formica, «El domicilio conyugal», $A B C, 7-11-53$, p. 9.

12. Teresa Loring, «Promoción político-social de la mujer durante los años del mandato de Francisco Franco» en AA.VV.: El legado de Franco, Madrid, Editora Nacional, 1997, pp. 593.

13. Fundamentalmente, tras esta reforma de 1958, la mujer casada podía figurar como testigo en los testamentos otorgados, y como tutora (con licencia del marido). Además se limitaban en cierta medida el poder de administración y disposición del marido sobre los bienes gananciales.

14. Inbal Ofer, "La legislación de género de la Sección Femenina de la FET. Acortando distancias entre la política de élite y la de las masas», Historia y politica, 15, 2006, pp. 219-240.

15. Teresa, Revista para todas las mujeres. Sección Femenina de FET y las JONS, Madrid, 1961, p. 92.

16. «Propuesta de Ley sobre el trabajo de ama de casa», $A B C$, 14-2-1968, p. 36. 
1959, se había celebrado en Madrid el I Congreso de la Familia Española con el objetivo de diagnosticar, tutelar y afianzar el lugar de la familia (considerada como institución de Derecho Natural) en España. Presidido por Manuel Fraga, contaba igualmente con un amplio comité integrado por personas afines al movimiento y provistas de la autoridad moral y profesional que requería el tratamiento de los asuntos allí abordados. Cumpliendo con ambos criterios y en representación de la Sección Femenina, acudía María Josefa Sampelayo, Regidora Central de Cultura de la organización falangista. De esta forma, en línea con el pensamiento más conservador respecto al papel de la mujer dentro de lo que se denominaba «orden natural», las Conclusiones publicadas tras la celebración del Congreso dejaron constancia de «la necesidad de permanecer la mujer fuera del hogar» era uno de los «obstáculos y dificultades para la vida familiar»; en consecuencia se recomendaba a las autoridades del Estado «que articulen un estatuto jurídico del trabajo doméstico en el cual se regulen [...] la formación profesional del mismo, su equiparación al resto de los trabajadores en orden a la seguridad social y a su retribución suficiente». Poco más adelante, se volvía a insistir en la misma idea al afirmar que «hay que retribuir el trabajo del padre [...], evitando así que la madre se vea obligada a trabajar fuera de casa» ${ }^{17}$.

El SESM, en pleno proceso de constitución durante aquel año de 1959, participó representado por tres de sus futuras integrantes en el I Congreso de la Familia, «donde inevitablemente se vieron obligadas a manifestar su disconformidad con varias de las tesis allí sustentadas ${ }^{18}$. No parece casualidad que, cuando en 1968 Primo de Rivera defendiera su propuesta de ley sobre el trabajo doméstico, recogiendo en gran parte lo que ya había sido planteado en aquel Congreso, los sectores más críticos con el tratamiento que el franquismo profería a las mujeres alertaran sobre la posibilidad de que esta ley funcionara como incentivo para hacer regresar al hogar a las mujeres que ya habían optado por incorporarse al mundo laboral. En este sentido, el SESM, activo desde hacía nueve años, manifestó públicamente el desacuerdo que había venido manteniendo desde diez años atrás hacia esta medida. Así, a los pocos días de la publicación de la propuesta de ley de la $S F$ en $A B C$, el Seminario presentó un artículo en el mismo diario titulado "El trabajo del ama de casa» donde no solo establecía una crítica férrea a sus implicaciones, sino que mostraba un compromiso con la promoción de la mujer en el mundo laboral que sería definitorio de su actividad hasta los años ochenta. El Seminario estimaba que con la aprobación de aquella ley se frenaría «la promoción de la mujer» y no se haría sino afianzar el supuesto (erróneo) de «que el trabajo doméstico es tarea exclusiva del ama de casa, no responsabilidad a compartir por todos los miembros de la familia»; además se preguntaban "¿cómo podrá la economía española prescindir en este momento de esas posibles fuerzas laborales

17. Conclusiones del I Congreso de la Familia Española, Madrid, Ediciones del Congreso de la Familia Española, pp. 7, 18 y 24.

18. SESM: «El movimiento feminista en España...», op. cit., p. 31. 
femeninas?». Para concluir, señalaban que «se advierte en esta proposición de ley un tono proteccionista y de privilegio hacia la mujer. Tenemos la triste experiencia de que las leyes de carácter proteccionista suelen volverse en contra del sujeto protegido» ${ }^{19}$.

\section{"LA PACIENTE LABOR DE UN SEMINARIO"20}

El artículo que presentaron en 1968 las integrantes del Seminario no fue firmado como "SESM», sino con sus nombres propios. Aunque para esta fecha ya llevaran a sus espaldas ocho años de intenso trabajo, no contaban, sin embargo, con reconocimiento oficial. Laffitte aseguraba que "para que el Grupo tuviese un carácter legal, ya que como he dicho nos reuníamos periódicamente un grupo de personas y podíamos estar incluso fuera de la ley, dada la etapa política por la que atravesábamos, decidimos solicitar permiso oficial, permiso que nos fue denegado ${ }^{21}$. Pocos años antes, con la creación de una Delegación Nacional de Asociaciones en 1957, se había iniciado una ligera permisividad hacia el reconocimiento de grupos y asociaciones. La puesta en vigor de la Ley de Asociaciones en 1964 había permitido la legalización de algunas asociaciones de mujeres, pero la gran mayoría (entre ellas el SESM) no lograría un reconocimiento oficial hasta finales de los años setenta ${ }^{22}$.

Aunque su actuación al margen de la legalidad sin duda debió dificultar algunas de sus acciones, la actividad del Seminario se mantuvo constante hasta bien entrada la década de los ochenta. Según Laffitte, el SESM era un grupo de trabajo "aconfesional, apolítico y democrático» ${ }^{23}$, que trató de abordar distintos temas en relación a la mujer desde los distintos ámbitos en los que estaban especializadas sus integrantes. Aún sin perder de vista esta descripción de su fundadora, la búsqueda de una definición para el SESM debe fundamentarse en la distinción entre el contexto de formación y promoción del asociacionismo católico femenino y el caso particular del Seminario, que si bien integraba a algunas de las mujeres promotoras de aquel asociacionismo confesional y progresista, no por ello debe ser definido en su totalidad como perteneciente a este. Dicho de otra forma, el hecho de que este grupo se constituyera a partir de la integración de mujeres de pensamiento católico liberal no debería llevarnos a pensar que el colectivo respondió a las mismas consignas y persiguió, durante

19. Lilí Álvarez, Concepción Borreguero, et. al.: «El trabajo del ama de casa», $A B C, 24-2-68$, p. 40.

20. Con estas palabras titulaba María Laffitte, fundadora y miembro hasta 1980 del SESM, un epígrafe de su autobiografía dedicado al Seminario. Cfr. María Laffitte, Mi atardecer..., op. cit., p. 122.

21. Idem., p. 124.

22. María Salas Larrazábal, y Mercedes Comabellas, «Asociaciones de mujeres y movimientos feministas», en Españolas en la transición. De excluidas a protagonistas (1973-1988). Madrid, Biblioteca Nueva, 1999, p. 29.

23. María Laffitte, Mi atardecer..., op. cit., p. 123. 
las décadas que estuvo activo, los mismos objetivos que el asociacionismo católico de los años sesenta y setenta. Más bien, el énfasis sostenido en la definición del SESM como «aconfesional, apolítico y democrático» constataba la necesidad de reconocerse como un grupo con carácter y principios definidos conjuntamente, y no derivados de las creencias particulares de algunas de sus integrantes, sí enroladas en movimientos confesionales (como el caso de Mary Salas en Acción Católica).

Este carácter diferenciado respecto a otros grupos viene constatado, además, por la voluntad de sus integrantes de abrir su espacio de estudio (físico, por el lugar donde se reunían, y conceptual, por los temas que abordaban) al mayor espectro posible de tendencias y posicionamientos, movidas por la intención de elaborar estudios científicos que reflejaran datos lo más objetivos posibles para sus investigaciones. En relación a ello, Laffitte afirmaba que el sistema de trabajo del grupo comenzaba con la elección consensuada de la problemática a tratar, tras lo cual se repartían entre ellas los diferentes aspectos del mismo acorde con las especializaciones de cada una, y se procuraba invitar a algún experto en el asunto para ampliar sus conocimientos. Así, con motivo de su investigación sobre mecanismos de agresividad acudió al Seminario, por ejemplo, el doctor Rof Carballo, y aseguraba Laffitte que también pasaron por el SESM a hablar sobre «sus especialidades» Jesús Moneo, Emiliano Aguirre, Carmen Llorca o María Aurelia Capmany, entre otros ${ }^{24}$.

No obstante, pese a su propia autodefinición como «aconfesional», en el primero de los proyectos desarrollados por el SESM aún se evidenciaba su deuda con valores católicos que consideraban a la religión como algo no solo compatible, sino también conveniente para la correcta evolución de la mujer moderna. En Habla la mujer. Resultado de un sondeo en la juventud actual, publicado en la editorial Cuadernos para el Diálogo en 1967 se recogían los datos y las conclusiones de un sondeo sociológico realizado por el SESM entre las mujeres madrileñas de diecisiete a treinta y cinco años de Madrid con el propósito de aclarar la situación de la mujer espańola en el proceso de modernización. Partiendo de la información recogida y analizada, el SESM afirmaba que las jóvenes españolas aún no se encontraban «insertas» en el movimiento juvenil contemporáneo, ya que su cultura y su modo de entender su lugar en la sociedad eran aún excesivamente deudores de lo que denominan «tradición». Para el Seminario, los datos demostraban la pasividad de las jóvenes y su «inmovilismo y escasa evolución», entendiendo por ello «la falta de actitud interna ante los problemas sociales»; también reflejaba la irresponsabilidad de las mujeres, probablemente a causa de la excesiva protección familiar, y la escisión entre el mundo masculino y el femenino, es decir, la poca confianza, complicidad y entendimiento entre los dos géneros. Por otra parte, como aspectos positivos, el SESM subrayaba que la mujer de los años sesenta se caracterizaba por su estima de los valores familiares y

24. María Laffitte, Mi atardecer..., op. cit., p. 125; SESM «El movimiento feminista en España...», op. cit., p. 31. 
su «sana moralidad sexual»; por ser religiosa y practicante por «convicción», no por obligación; y por su bondad, generosidad y optimismos, unos rasgos que, aunque el Seminario ve con buenos ojos, no duda en atribuir en parte a un "exceso de ingenuidad y conformismo». Para el SESM estas conclusiones mostraban que las jóvenes españolas requerían un mayor «apoyo y estímulo por parte del Estado, la Sociedad y la Familia» ${ }^{25}$. Por otro lado, la publicación de Habla la mujer en Cuadernos para el Diálogo no hacía sino señalar el vínculo que el SESM quiso establecer entre sus investigaciones y la línea editorial de aquella empresa, y aunque ello no quiera decir que el Seminario se reconociera a sí mismo como vinculado al pensamiento democristiano (del que sí era deudora la editorial y la revista del mismo nombre), sí se puede hablar de un común compromiso por los problemas sociales y de una perspectiva católica aperturista compartida.

Tras la aparición del libro, la prensa recogió importantes reseñas que señalaban tanto la relevancia del trabajo realizado como la continuidad que este suponía respecto a las trayectorias intelectuales de las integrantes del Seminario. Sin embargo, solo un artículo firmado por Mercedes Formica ponía las conclusiones de este trabajo en relación a la contestación que el SESM había publicado en el $A B C$ a propósito de la propuesta de ley de la SF sobre el trabajo doméstico de las mujeres. Además de calificar a Habla la mujer de "profundo y exhaustivo", Formica volvía a retomar las palabras exactas con las que el SESM había explicitado su crítica, demostrando con ello no solo su acuerdo al respecto, sino también haciendo suyo el argumento sobre el doble filo de las políticas proteccionistas con las mujeres ${ }^{26}$.

A comienzos de la década de los setenta, $\mathrm{y}$ «tras muchas dudas y vacilaciones», algunas de las integrantes del SESM participaron en el I Congreso Internacional de la Mujer organizado por la Sección Femenina y celebrado del 7 al 14 de junio de $1970^{27}$. La indecisión sobre la posible colaboración en el evento no pudo venir sino del temor a intervenir en un acto de tintes tan oficialistas y de posibilidades de discusión tan limitadas como este promovido por la SF. No obstante, debieron pesar en su decisión final la oportunidad que aquella reunión les brindaba de conocer la actividad y los proyectos de otros grupos feministas, así como las posibilidades, aunque ciertamente limitadas, de promover algún tipo de reforma dentro del espacio de «modernización» que la SF, como brazo del poder, estaba resuelta a permitir. De hecho, justamente porque la organización falangista había sabido percibir la necesidad de dar una cobertura legal a los cambios -o incluso impulsarlos, tal y como se ha visto arriba ${ }^{28}$, y porque había sido consciente de que su supervivencia dentro del régimen pasaba por la evolución hacia un discurso que pudiera seguir captando

25. SESM: Habla la mujer. Resultados de un sondeo en la población actual. Madrid, Cuadernos para el Diálogo, 1967, p. 199-200.

26. Mercedes Formica, «El próximo Congreso Internacional de la Mujer», $A B C$, 3-3-68, p. 89.

27. SESM: «El movimiento feminista en Espańa...», op. cit., p. 32.

28. Inbal Ofer: op. cit., pp. 222-227. 
y encuadrando a las mujeres bajo su organización, la SF se decidió a actuar en los años setenta con una vocación limitadamente conciliadora convocando dos eventos: el primero, el I Congreso Internacional de la Mujer, en 1970; y posteriormente la más amplia celebración del Año Internacional de la Mujer en 1975.

El I Congreso Internacional de la Mujer tenía como fin el estudio de la mujer en España desde ámbitos tan diferentes y específicos como el educativo, el laboral, el social, el económico o el político. Como ha indicado Díaz Silva, la actitud de las mujeres españolas respecto a este acontecimiento fue desigual, puesto que produjeron manifestaciones tanto de rechazo y oposición en los medios, como de adhesión más o menos entusiasta al evento. Este segundo caso fue el de colectivos como la Fédération Internationale des Femmes des Carrières Juridiques, la Asociación Española de Mujeres Juristas, o las Asociaciones de Amas de Casa; y el de particulares, como Mary Salas o María Laffitte ${ }^{29}$, que participaron conjuntamente en la presentación de la ponencia «Mujer y educación» e integraron varias comisiones. Según señalaba el propio SESM una década después, a las miembros del Seminario que participaron en el Congreso les «costó Dios y ayuda tratar de temas como la coeducación, palabra prácticamente vetada en aquellas sesiones, pero introducida por subterfugios tan ingenuos como "clases con niños y niñas", y cosas por el estilo" ", mientras que Salas y Comabellas aseguraban que las intervenciones del grupo sobre esta y otras cuestiones «levantaron polémica» ${ }^{31}$. Por su parte, años después del evento, Mary Salas afirmaba que formaron "como un grupo de presión" (presumiblemente, las que pertenecían al SESM y con probabilidad participantes de opiniones concordantes); «yo estuve en educación -afirmaba- y fue una pelea tonta. Se quería introducir la coeducación y al final entró educación para niños y niñas, mixta, porque la palabra coeducación no se podía decir entonces ${ }^{32}$.

La importancia que las integrantes del Seminario otorgaban a la reforma de la educación quedó nuevamente reflejada, apenas dos años después, en la obra colectiva del SESM Mujer y aceleración histórica, publicada en la colección «Los Suplementos» de Cuadernos para el Diálogo en 1972. Laffitte señalaba a finales de esta década la intención explícita que tenía aquel estudio: era una «respuesta a la publicación del Libro Blanco para la reforma de la educación en España, con el que no estábamos totalmente de acuerdo en lo referente a la mujer ${ }^{33}$. El Libro Blanco de la Educación de 1969 había precedido a la Ley General

29. Elena Díaz Silva, «El Año Internacional de la Mujer en España: 1975», en Cuadernos de Historia Contemporánea, 13, 2009, pp. 319-339, p. 322.

30. SESM: «El movimiento feminista en España», en Concepción Borreguero, Elena Catena et al., op. cit., pp. 31-32.

31. María Salas Larrazábal y Mercedes Comabellas, «Asociaciones de mujeres y movimientos feministas", op. cit., p. 28.

32. Giulia Gadaleta, Il movimiento feminista in Spagna durante la transizione (1974-1979. Bologna, Università degli Studi di Bologna, 1998 (Entrevistas en Anexo), en Elena Díaz Silva, op. cit, p. 323.

33. María Laffitte, Mi atardecer..., op. cit., p. 124. 
de Educación de 1970 con la que se iniciaba la enseńanza mixta en España. La ambigüedad de sus planteamientos se había puesto de manifiesto desde su implantación, ya que esta norma no cuestionaba los valores tradicionales y el rol hogareño de las mujeres, sino que continuaba promoviendo para ellas los objetivos de ser esposas y amas de casa ${ }^{34}$. En Mujer y aceleración histórica, el SESM incidía en esta continuidad de la discriminación por sexo en el ámbito de lo educativo: «El Estado, en este aspecto, no ha puesto mucho interés, hasta el presente, en modificar esta mentalidad y, en muchos casos, ha frenado ostensiblemente los intentos progresistas de incorporar plenamente a la mujer a la sociedad española ${ }^{35}$. A la crítica la acompañaban propuestas concretas que defendían la urgente profesionalización del trabajo femenino y la necesidad de un régimen de coeducación ante la insuficiencia de una enseñanza mixta pero diferenciada por sexo. Cabría suponer, a tenor del título de la ponencia presentada en el Congreso Internacional de la Mujer, «Mujer y educación», y del contenido del libro poco después publicado, y presumiblemente preparado en la misma fecha de celebración de aquel evento, que la exposición pública de sus opiniones, así como el diálogo compartido con el resto de colectivos que concurrieron al Congreso, fueron determinantes tanto para «testar» las hipótesis con las que estaba trabajando el SESM, como para orientar la marcha del libro. Por otra parte, ello no estaría lejos de la dinámica de trabajo que según Laffitte había adquirido el grupo, que -recuérdese- siempre estaba atenta a la posibilidad de contrastar sus puntos de vista con los de personas especializadas en la materia.

Aparte de constatar la importancia que las integrantes del Seminario otorgaban a una educación igualitaria, para Moreno Seco esta publicación de 1972 confirmaría también la evolución del SESM hacia un abierto feminismo, dado que en ella las autoras definían a la sociedad espańola como "patriarcal» y mostraban su rechazo a la mentalidad tradicional, impregnada de la «más clásica misoginia» ${ }^{36}$. De esta forma, el afianzamiento de un pensamiento feminista, fuertemente crítico con la atribución de roles de sumisión a las mujeres fue siendo más patente en el SESM conforme avanzó la década de los setenta, en paralelo al fortalecimiento del pensamiento y del asociacionismo feminista que tuvo lugar en estos años. Prueba de ello fue su participación en plataformas y jornadas feministas surgidas a mediados de los setenta, como la Plataforma de Organizaciones y Grupos de Mujeres de Madrid, constituida a finales de 1974 con vistas a la preparación de un programa común para la celebración en 1975 del Año Internacional de la Mujer. Junto con el SESM,

34. Inés Alberdi, «La educación de la mujer en España» en Concepción Borreguero y Elena Catena, et. al., La mujer espańola..., op. cit., pp. 71-81; Consuelo Flecha García, «Las mujeres en el sistema educativo español» en Teresa Marín Eced, y María del Mar Pozo Andrés (coords.), Las Mujeres en la construcción del mundo contemporáneo. Cuenca, Diputación Provincial, 2002; Teresa González Pérez, «Mujeres, educación y democracia», Revista de Educación, 351, 2010, pp. 337-359.

35. SESM: Mujer y aceleración histórica, Madrid, Cuadernos para el diálogo, 1970, p. 51-52. 36. Mónica Moreno Seco, "Cristianas por el feminismo y la democracia...», op. cit., p. 142. 
participaron un conjunto heterogéneo de grupos (Asociación Española de Mujeres Universitarias; Asociaciones de Amas de Casa; Asociaciones de Mujeres Separadas Legalmente; Movimiento Apostólico Seglar; entre otros ${ }^{37}$ que daban cuenta de la multiplicidad de cauces de concienciación feminista y de movilización política que se estaban activando en estos ańos centrales de la década.

Precisamente con motivo del Año Internacional de la Mujer declarado por la UNESCO, tuvo lugar la celebración en diciembre de 1975 de las Primeras Jornadas de Liberación de la Mujer organizadas por la Plataforma de Grupos Feministas. Estas Jornadas, que en parte eran respuesta a las conmemoraciones oficialistas del Año Internacional de la Mujer, hicieron posible la reunión de la mayoría de las organizaciones o grupos que durante los anteriores ańos de dictadura habían ido fraguando un pensamiento feminista, muy difuso y contradictorio en ocasiones, pero mantenido como auténtica resistencia al dogma sobre la mujer promovido por el régimen. Los debates se centraron en temas tan significativos como la educación, la familia, el divorcio, el trabajo, la mujer rural, la situación en los barrios, el movimiento feminista, la sexualidad, el aborto y la discriminación legal, etc ${ }^{38}$. La implicación de las componentes del SESM en este foro fue una señal inequívoca de su voluntad de integrarse en el movimiento feminista, y la celebración de este evento les daría, además, la oportunidad de comenzar posicionarse respecto a uno de los asuntos que se constituyó tempranamente como polémica entre todos los grupos: la de si la acción política debía ser simultánea a la acción feminista, o bien había que considerar el feminismo como una alternativa global a la sociedad dominada por el hombre ${ }^{39}$; según Laffitte, el SESM optó por la doble militancia ${ }^{40}$. Su elección no hay que entenderla como la cercanía a una determinada corriente política, sino como el único posicionamiento válido para poder sostener la intención primera de hacer del SESM un grupo «apolítico». Así, la adopción de la doble militancia aparecía como una vía eficaz para mantener su actividad como feministas sin tener que hacer de ello una actividad "política", y conservando la posibilidad de que cada una de las integrantes pudiera afirmarse en su convicciones políticas sin que ello afectara al conjunto del Seminario.

Continuando en esta línea de afianzamiento de su feminismo, en 1977 el Seminario publicaba Diagnosis sobre el amor y el sexo, esta vez no en Cuadernos para el Diálogo, sino en la editorial Plaza \& Janés de Barcelona. El proyecto partió de la intención de investigar la afectividad de la pareja humana: «limitamos nuestro estudio a los jóvenes de 18 a 21 ańos, porque

37. Amparo Moreno Sardá, Mujeres en lucha: el movimiento feminista en España. Barcelona, Anagrama, 1977.

38. Mary Nash, "La construcción de una cultura política desde la legitimidad feminista», en Ana Aguado y $\mathrm{M}^{\mathrm{a}}$ Teresa Ortega (eds.), Feminismos y antifeminismos. Culturas politicas e identidades de género en la España del siglo XX. Valencia, Granada, Publicaciones de la Universidad de Valencia, 2011.

39. SESM: «El movimiento feminista en España», op. cit., p. 32.

40. María Laffitte, Mi atardecer..., op. cit., p. 127. 
entendemos que ya han pasado la adolescencia y todavía no están demasiado moldeados por la sociedad", explicaban las autoras ${ }^{41}$. Esta primera recogida de datos correspondería al «Sondeo analítico», mientras que la segunda parte, el «Sondeo de opinión», con preguntas más abiertas y respuestas más reflexivas, estaba dirigido a los «testigos de excepción», personas «maduras y de diferentes tendencias ideológicas, todos ellos conectados de algún modo con las nuevas generaciones ${ }^{42}$. Por una parte este último hecho corrobora las palabras de Laffitte, recogidas más arriba, en las que recordaba la voluntad que siempre tuvo el SESM de rodearse de personas doctas en las cuestiones que se proponían abordar ${ }^{43}$. Por otra, su intención de restringir el espectro de edades del sondeo analítico a las comprendidas entre los 18 y los 21 años, revelaba su propósito de enfocar la investigación hacia las generaciones nacidas a partir de 1956. Quienes habían crecido en aquellos años, aunque hubieran conocido, y sin duda en gran parte vivido, la restricción de la férrea moral del franquismo, también habían tenido posibilidad de experimentar los nuevos modelos de conducta sexual que progresivamente habían empezado a calar entre los más jóvenes.

En este sentido, la preocupación del Seminario por la relación afectividadsexualidad no era sino una pieza más del engranaje feminista que en esta década se estaba poniendo en marcha para reivindicar un conocimiento más profundo de la sexualidad femenina, una práctica y disfrute de la misma más libre, y una legislación que amparara aquello que en la práctica ya se estaba realizando. Así, fueron muchos los colectivos que incidieron en un aspecto u otro de este movimiento. En línea con aquellos colectivos, y manifestando una preocupación firme por el conocimiento profundo de esta problemática social, las conclusiones extraídas por las autoras del estudio Diagnosis sobre el amor y el sexo, más renovadoras que las dos obras anteriores, advertían que se estaba asistiendo a mediados de la década de los setenta a una evolución de las relaciones interpersonales de los sexos, puesto que caracterizaba a la juventud «el deseo de superar los tabúes sexuales, movida por la convicción de que todo lo natural y espontáneo es bueno». Además, según los datos recogidos, el Seminario se veía en la posibilidad de afirmar que «las relaciones entre los sexos tienen un talante más libre de inhibiciones y menos exclusivista, lo cual facilita la liberación de obsesiones sexuales y disminuye el sentido posesivo de la pareja». El SESM

41. SESM: Diagnosis sobre el amor y el sexo. Una indagación entre la juventud universitaria. Barcelona, Plaza \& Janés, p. 10.

42. Ibidem.

43. Entre los que el SESM denominó «testigos de excepción» se encontraban un psicólogo (José Luis Pinillos), dos novelistas (Miguel Delibes y Francisco Umbral), dos sacerdotes (Miguel Benzo y Jesús Burgaleta); médicos (Alfonso Álvarez Villar, Fernanda Monasterio y José Ramírez Guedes), dos abogados (Eduardo Cierco y María Telo), una asistenta social (Josefina Merchán), una profesora de biología (María Luisa Martínez Frías), un profesor y crítico literario (Andrés Amorós), un publicista (Enrique Miret), una dirigente de obras católicas (Pilar Bellosino) y un crítico teatral (Ricardo Doménech). Cfr. SESM: Diagnosis sobre el amor y el sexo..., op. cit., pp. 65-66. 
también destacaba la «exigencia de una mayor autenticidad en el amor y en el matrimonio" y el hecho de que las relaciones sexuales prematrimoniales fueran cada vez más frecuentes y socialmente admitidas. Además, se posicionan respecto al polémico asunto del divorcio: «el elevado número de separaciones que ya se produce entre nosotros es prueba evidente de la necesidad de pasar de una legislación civilista prohibitiva a otra que reconozca y regule el divorcio» ${ }^{44}$.

En 1977, mismo año de esta publicación, el SESM se pudo legalizar, y en sus estatutos reflejó una serie de propósitos que Salas y Comabellas describieron como utópicos. Según las autoras, su finalidad consistía en "contribuir a crear una sociedad distinta, más humana, en la que las relaciones no sean frustrantes para nadie, sino estimulantes y creadoras». El SESM se proponía, según sus objetivos, cambiar la mentalidad tradicional a través de una educación crítica y transformar las relaciones interpersonales de acuerdo con los presupuestos del feminismo. Así mismo, se mostraba a favor de una ley que regulara el divorcio; de la información sobre anticonceptivos y de que las responsabilidades familiares fueran asumidas por el padre y la madre indistintamente. Igualmente, demandaban la coeducación en todos los niveles de la enseñanza y la aplicación rigurosa del principio de igual retribución por trabajo de valor equivalente ${ }^{45}$. En 1980, Laffitte dejaba de dirigir el Seminario «por razones de edad y por haber abandonado el casco urbano para vivir en sus cercanías» y era nombrada por sus integrantes "presidenta de honor vitalicia».

Finalmente, durante la primera mitad de la década de los ochenta, y antes de disolverse en 1986 "por acuerdo unánime y amistoso» después del fallecimiento de Laffitte y de Consuelo de la Gándara ${ }^{46}$, el SESM coordinó la publicación de La mujer española: de la tradición a la modernidad (1960-1980), en la editorial Tecnos de Madrid ${ }^{47}$. El libro llevaba un prólogo de Laffitte en el que la escritora, ya como presidenta de honor, subrayaba la continuidad que esta publicación suponía respecto a la suya de 1964, La mujer en España. Cien años de su historia. 1860-1960 ${ }^{48}$. Si bien este último había servido a Laffitte como punto de partida para las investigaciones colectivas del SESM, la obra que ahora dirigía el Seminario era tanto una prolongación de la de 1964, como un punto y final a las dos décadas y media de trabajo del grupo. El libro de 1986 se pensó como una obra colectiva que abordara la historia de la mujer desde los años sesenta a partir de once temas encomendados a distintas especialistas.

44. SESM: Diagnosis sobre el amor y el sexo... op. cit., p. 153-157.

45. María Salas Larrazábal y Mercedes Comabellas, «Asociaciones de mujeres y movimientos feministas", op. cit., p. 29.

46. María Salas Larrazábal y Mercedes Comabellas, op. cit., p. 29.

47. La obra se publicó bajo la dirección de Concha Borreguero, Elena Catena, Consuelo de la Gándara y Mary Salas. Sin embargo, ya desde las primeras páginas hicieron constar que se trataba de un proyecto en el que habían trabajado como miembros del SESM. Cfr. Concha Borreguero y Elena Catena, La mujer española..., op. cit., p. 8.

48. María Laffitte, «Prólogo», en Concha Borreguero y Elena Catena, La mujer española..., op. cit., p. 9-10. 
Aparte de la dirección de la obra, el SESM preparó el capítulo titulado «El movimiento feminista en Espańa. De 1960 a 1980». En cierto modo, las autoras fueron conscientes de que narrar la historia de estas dos décadas significaba en gran medida relatar su propia experiencia. Partiendo de esta certeza, subrayaron sin ambages su protagonismo en este periodo y señalaron la prontitud de su surgimiento en 1960, equiparándolo al de la fundación del Movimiento Democrático de Mujeres (MDM) en 1965. Además, dedicaron un amplio espacio -en proporción al destinado a otros grupos- a narrar los propósitos, el modo de funcionamiento del SESM y los eventos en los que sus integrantes participaron. Por supuesto que el texto dejaba constancia del papel jugado por otras muchas organizaciones de todo el país y de los encuentros y desencuentros que se fueron produciendo entre ellas conforme evolucionaron sus posturas. Sin embargo, e independientemente de la muy positiva labor historiográfica que el SESM desarrollara en este capítulo, resultan muy elocuentes las menciones que este hacía sobre sí mismo a la altura de 1986. A sabiendas de que sería su última publicación, el Seminario unió la historia colectiva del feminismo español con la enfatización de algunos datos de su trayectoria, dejando un rastro de su propia biografía entrelazada con la del movimiento de mujeres, y asegurando con ello (como el autobiografiado trata siempre garantizar mediante su escritura) que el SESM sería tenido en cuenta en la narración del feminismo español que entonces comenzaba a historiarse a sí mismo.

\section{Conclusiones}

A pesar de las intenciones de sus integrantes, el SESM no ha contado con estudios que profundicen en su trabajo y aborden sus particularidades. Aunque sí existen investigaciones que reseñan y describen su labor, esta no ha sido indagada en profundidad, en gran medida porque sus publicaciones apenas han sido tenidas en cuenta como vectores esenciales para dilucidar la evolución su pensamiento colectivo. Sin embargo, la revisión de los estudios que elaboró e hizo públicos el SESM, junto con el rastreo de su participación en las plataformas del movimiento de mujeres, dibujan una trayectoria sólida y decidida, nacida de la firme convicción de la que era necesario conocer las circunstancias para poder plantear reivindicaciones ajustadas a las necesidades.

Como resulta de sobra conocido, el régimen franquista puso en marcha un aparato represivo que estableció la rígida censura de cualquier espacio o medio que posibilitara el cuestionamiento de las normas de género o el planteamiento de identidades alternativas. Ante ello, y en línea con los parámetros generales de actuación que siguieron otras asociaciones feministas, el SESM elaboró dos tipos de respuestas colectivas hacia las discriminaciones formales e informales de las que eran víctimas las mujeres de su tiempo. De este modo, y aunque ellas nunca hicieran en sus publicaciones una diferenciación efectiva de estos dos cauces de contestación hacia sendos modelos de opresión, es fundamental que, a modo de conclusión, los revisemos por separado, ya que de esta manera 
se entenderá mejor que fuera precisamente en la articulación de ambos donde radicara el éxito de los mensajes del SESM.

Por un lado, el Seminario denunció la discriminación formal instaurada mediante cauces institucionales que, como en el caso de la legislación, abocaban a las mujeres a una situación de tutelaje y desposesión jurídica. Este fue el caso de su participación en tribunas públicas, como el diario $A B C$, donde en 1968 mostraron su diametral desacuerdo con la propuesta de ley sobre el trabajo doméstico y extradoméstico de la SF. También vertieron duras críticas contra las leyes de educación, uno de los asuntos que el Seminario abordó con mayor dedicación. Así lo hicieron en su obra colectiva de 1970 Mujer y aceleración histórica, aunque, recuérdese, su interés por la deficiente formación de la mujer ya había sido manifestado en el libro Habla la mujer, de 1967. De igual modo actuarían con asuntos tan polémicos y tan debatidos en los foros feministas como el divorcio, para el que reclamaron una regulación que sustituyera a la anterior normativa. En este sentido, una constante que no puede pasar inadvertida fue la denuncia constante del SESM hacia la hipocresía que se parapetaba tras leyes paternalistas, que decían proteger aquello que en realidad estaban oprimiendo. Al declarar en su artículo de 1968 en $A B C$ haber tenido «la triste experiencia de que las leyes de carácter proteccionista suelen volverse en contra del sujeto protegido", el Seminario hacía toda una declaración de intenciones respecto a su modo (feminista) de interpretar la legislación a la que como mujeres aún estaban sujetas.

Por otra parte, el Seminario también elaboró sus propias respuestas críticas en contra de las prácticas sexistas y discriminatorias informales que, por ampararse bajo la apariencia de convenciones socioculturales, resultaban más difíciles de dilucidar, denunciar, y revertir. Por ello, ya en su obra de 1967 mostraban preocupación por el «movimiento cultural juvenil» en el que las jóvenes españolas parecían no integrarse, o por la creación de lo que denominaban «un estado de opinión favorable a la intervención de la mujer, en igualdad de condiciones con el hombre, en el trabajo y en la creación de una sociedad moderna». Indudablemente, para el Seminario fue un objeto de estudio central la visión que la sociedad tenía de las mujeres y el modo por el cual estas visiones, en su mayoría tradicionalistas o contrarias a la emancipación, acababa por materializarse en las vidas concretas de aquellas. No en vano, el SESM fundamentó sus investigaciones en sondeos y entrevistas que, junto con los datos estadísticos, les proveyó de una visión general del modo de sentir y de percibir los cambios históricos de las mujeres y los jóvenes de su tiempo.

De este modo, la efectividad de la labor del SESM a lo largo de aquellos residió en su capacidad de atender al análisis de la situación de la mujer a estos niveles, el institucional u oficial, y el sociocultural. Para ello, pusieron el foco sobre los discursos elaborados desde los dos ámbitos, y contrastaron sus impresiones tanto con experiencias cotidianas, como con las elaboraciones teóricas de profesionales de su tiempo. Y aunque su sistema de trabajo apenas cambiara durante estos años, no se puede decir que su vocación feminista, e incluso su transgresión respecto a la oficialidad, se mantuviera constante 
durante todo el periodo de su actividad. Más bien, fue ampliándose, modificándose y adoptando las reivindicaciones, cada vez más exigentes, del movimiento feminista al que nutría y del que, a su vez, se proveía de ideas. Por ello es importante saber ver las particularidades del SESM dentro del conjunto más amplio del movimiento de mujeres del tardofranquismo y la transición democrática, porque justamente así se puede conocer de qué modo caminos propios fueron cruzándose, conectando con otros, e intercambiando los elementos con los que, en estos años, comenzaría a negociarse y a construirse una cultura política propiamente feminista. 
